\title{
Immediate retrieval of a maldeployed lumen-apposing metal stent from a walled-off cavity
}

A 46-year-old woman presented with a large walled-off collection, likely related to a prior episode of pancreatitis. Percutaneous drainage had been attempted at an outside institution, but the collection recurred. She was transferred urgently to our hospital in multiorgan failure with sepsis and abdominal pain.

Computed tomography (CT) scanning showed a large, mature left upper quadrant collection ( $\triangleright$ Fig.1). Endoscopic ultrasound (EUS)-guided transluminal drainage was performed. A transgastric location was accessed with a 19-gauge needle. A cystogastrostomy was created using a $15 \times 10-\mathrm{mm}$ cautery-assisted lumen-apposing metal stent (LAMS; Boston Scientific, Marlborough, Massachusetts, USA). The distal flange was deployed in the cavity; however, because of the mass effect from the stomach ( Fig.2), deployment of the proximal flange was difficult. It was clear both endoscopically and on EUS that the proximal flange had not deployed intraluminally (-Video 1 ).

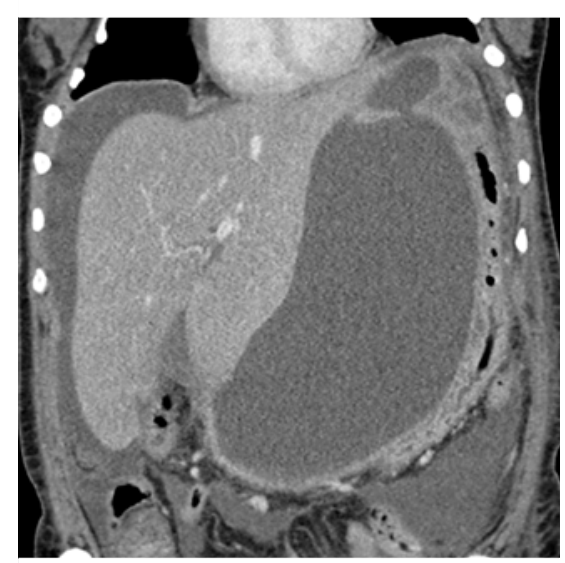

- Fig. 1 Contrast-enhanced computed tomography scan showing a large walledoff collection in the left upper quadrant that is compressing the stomach.
Maintaining wire access to the collection allowed passage of a second LAMS to control the defect without creating a second cystogastrostomy. A single-channel therapeutic upper gastrointestinal endoscope was passed through the second LAMS into the collection. The maldeployed LAMS was grasped using a rattooth forceps under fluoroscopic guidance, suctioning the collection down to bring the stent closer and opening and closing the forceps like "Pac-man" ( Fig.3). To avoid dislodgement of the second LAMS, the maldeployed LAMS was pulled through the channel of the endoscope.

In summary, we present a case of immediate retrieval of a maldeployed LAMS and salvage of the original cystogastrostomy. The use of multimodal imaging white-light endoscopy, EUS, and fluoroscopy - during the deployment process is critical. If maldeployment occurs, immediate recognition will allow same-session rescue to be attempted. Maintaining wire access to the collection to facilitate

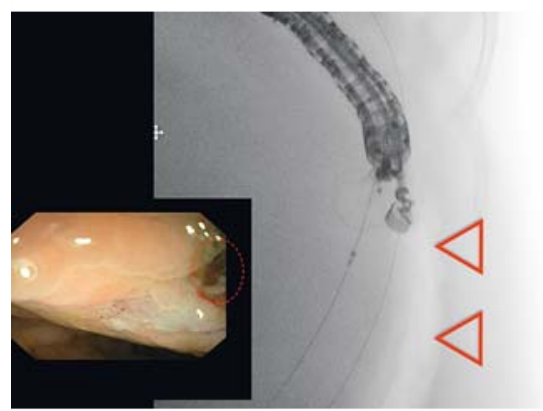

-Fig. 2 Endoscopic and fluoroscopic images during deployment of the lumenapposing metal stent (LAMS) across the cystogastrostomy showing the limited intragastric space owing to the mass effect from the collection (red arrows) and the absence of the proximal portion of the LAMS endoscopically (red dashed circle) indicating its deployment in the cavity. deployment of a second LAMS and subsequent retrieval was crucial in this example. Finally, withdrawal of the LAMS through the channel of a therapeutic endoscope presents a safe removal option.

Endoscopy_UCTN_Code_CPL_1AL_2AD

Competing interests

Martin Freeman has acted as a consultant for Boston Scientific, Cook Medical, and Xlumena. Stuart Amateau has acted as a consultant for Merit Endoscopy, Boston Scientific, US Endoscopy, and Neurotronic, and has received research support from Cook Medical. Nabeel Azeem has no conflicts to report.

The authors

Nabeel Azeem, Martin L. Freeman, Stuart K. Amateau

Division of Gastroenterology and Hepatology, University of Minnesota, Minneapolis, Minnesota, USA

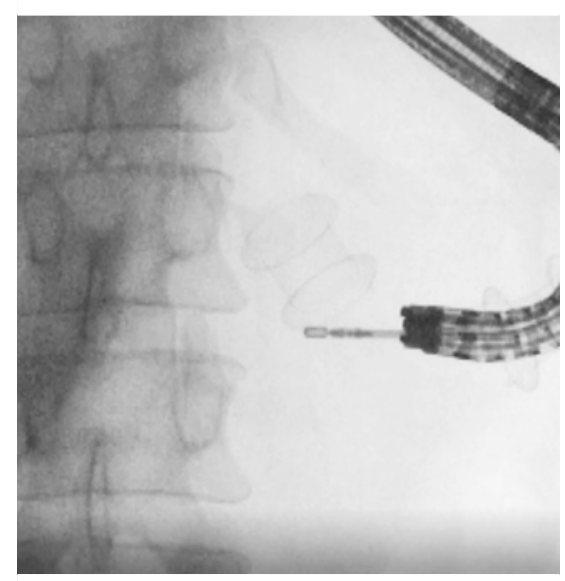

> Fig. 3 Fluoroscopic image showing a single-channel therapeutic upper gastrointestinal endoscope that has been advanced across the lumen-apposing metal stent at the cystogastrostomy and the maldeployed stent in the cavity being grasped with a rat-tooth forceps. 


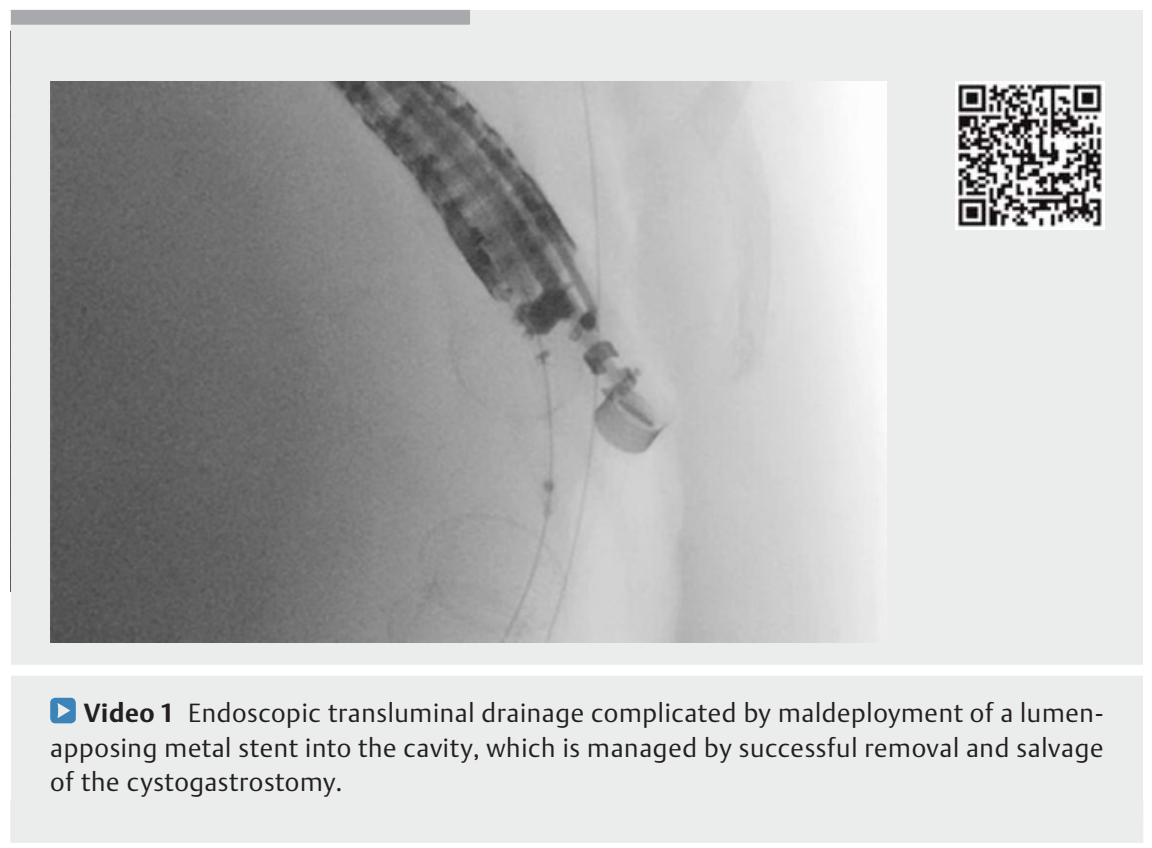

Corresponding author

\section{Stuart K. Amateau}

University of Minnesota, MMC 36, 420

Delaware St SE, Minneapolis, MN 55455, USA

amateau@umn.edu

\section{Bibliography}

DOI https://doi.org/10.1055/s-0043-124759

Published online: 12.1.2018

Endoscopy 2018; 50: E76-E77

(c) Georg Thieme Verlag KG

Stuttgart · New York

ISSN 0013-726X

\section{ENDOSCOPY E-VIDEOS}

https://eref.thieme.de/e-videos

Endoscopy E-Videos is a free

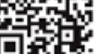
access online section, reporting on interesting cases and new techniques in gastroenterological endoscopy. All papers include a high quality video and all contributions are freely accessible online.

This section has its own submission website at

https://mc.manuscriptcentral.com/e-videos 